Supplement of Saf. Nucl. Waste Disposal, 1, 247-248, 2021

https://doi.org/10.5194/sand-1-247-2021-supplement

(C) Author(s) 2021. CC BY 4.0 License.

Supplement of

\title{
Including Civil Society in R\&D Projects on Radioactive Waste Management: interactions with Civil Society (ICS) in EURAD
}

Julien Dewoghelaere et al.

Correspondence to: Julien Dewoghelaere (julien.dewo@ mutadis.fr)

The copyright of individual parts of the supplement might differ from the article licence. 


\section{eurad

INCLUDING CIVIL SOCIETY IN R\&D PROJECTS ON RADIOACTIVE WASTE MANAGEMENT: INTERACTIONS WITH CIVIL SOCIETY (ICS) IN EURAD

BASE Interdisciplinary Research Symposium, Session 4B

10 November 2021 • Julien Dewoghelaere

The project leading to this application has received funding from the European Union's Horizon 2020 research and innovation programme under grant agreement $n^{\circ} 847593$.

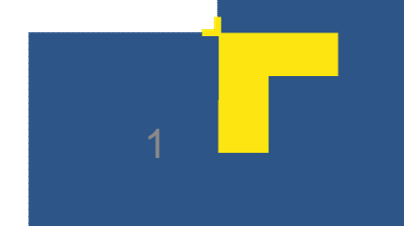




\section{EURAD KNOWLEDGE MANAGEMENT \& NETWORKING PROGRAMME}

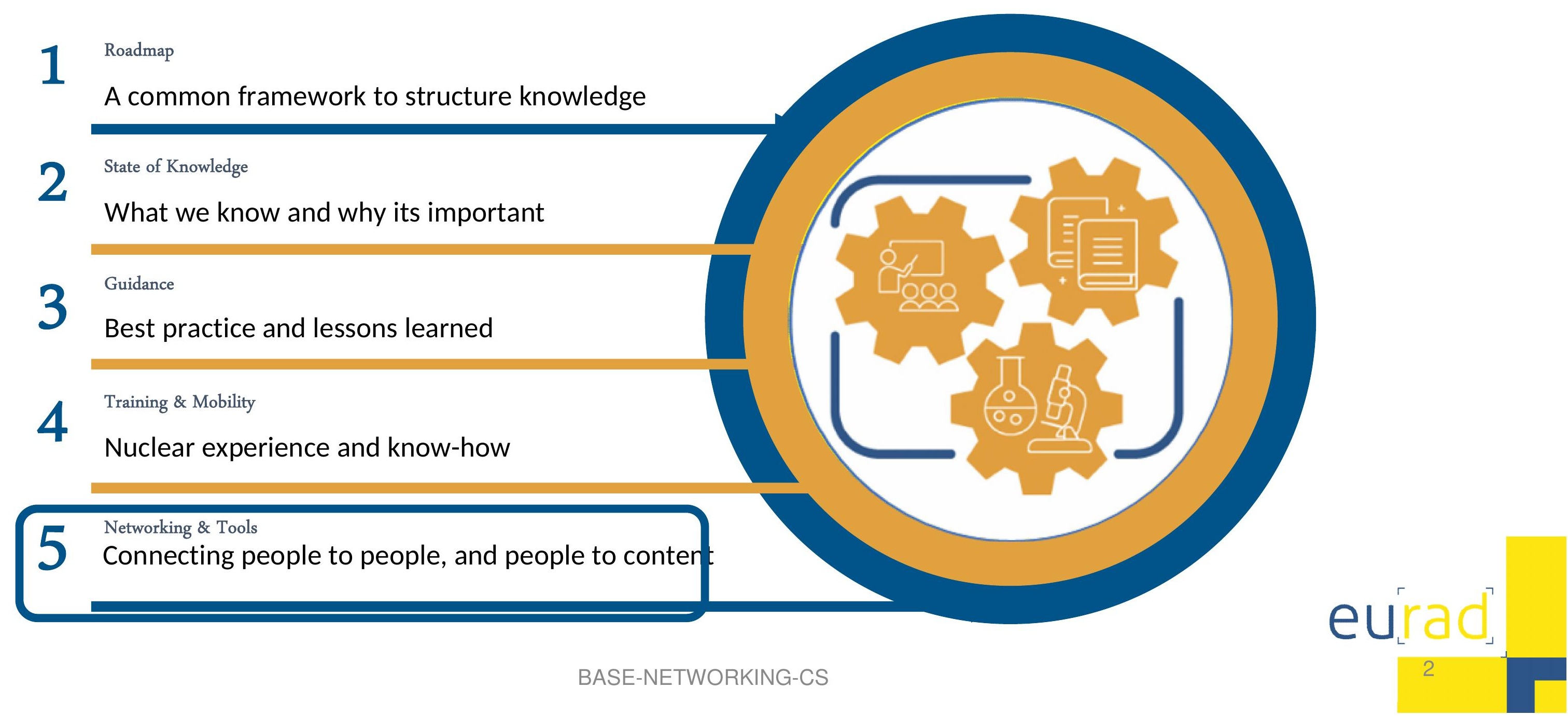




\section{INTERACTIONS WITH CIVIL SOCIETY : WHY ?}

- Civil Society participants have specific concern on RWM safety, they are not research partners

- They are involved in the perspective of Aarhus Convention implementation

- One objective of EURAD is to allow interactions between all categories of actors : WMOs, TSOs, REs and Civil Society ("3+1 Dialogue")

- Such interactions aim at improving mutual understanding of how and to what extent RD\&D activities on RWM make sense and contribute improving decisions

- It shall also contribute to developing ideas, propositions and methodologies on

- how to interact with Civil Society on scientific and technical result

- how to deal with uncertainties

- how to interact with Civil Society in order to promote mutual benefit of available knowledge 


\section{ICS ACTIVITIES : HOW ? - DOUBLE WING MODEL}

- Model of pluralistic interactions developed and tested in previous projects (SITEX-II, JOPRAD)

- CS experts with technical and socio-technical background or/and experience on the involvement of CS in scientific and technical issues,

- involved in EURAD activities through NTW, translating scientific/technical results for exchanging with

- A larger group of CS representatives (CSOs, representatives of local communities, individual experts)

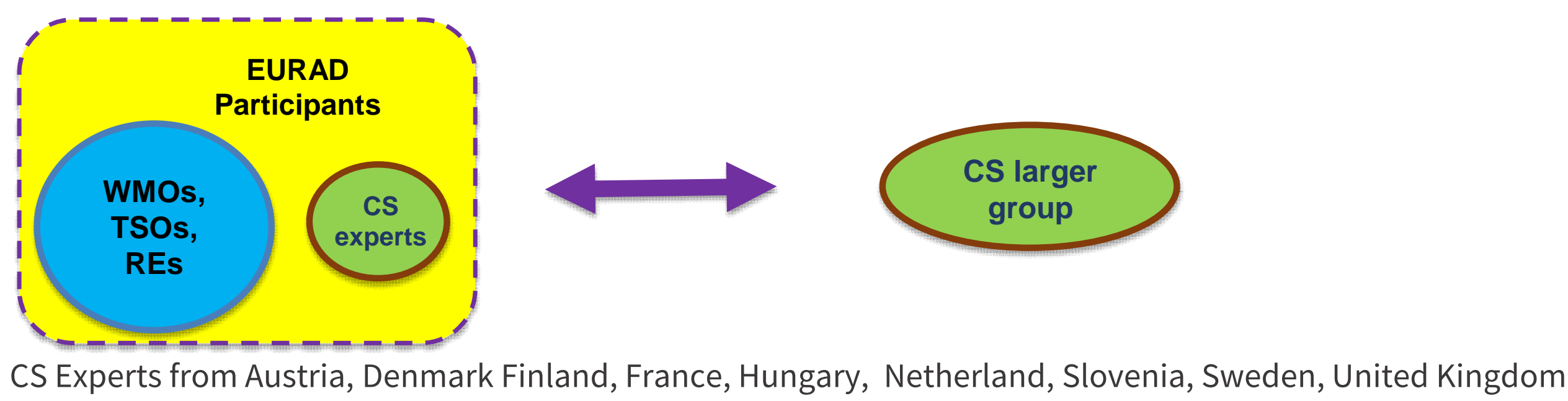




\section{CS LARGER GROUP - COMPOSITION}

- Identification of potential members: 61 potential identified candidates coming from 25 countries

- Several categories of participants

- 2 categories of actors and organisations:

- European and national associations

- local stakeholders (individuals and representatives of local communities, partnerships, local associations)

- 22 members (according to the available resources to cover the physical participation) - group finalized in March 2020

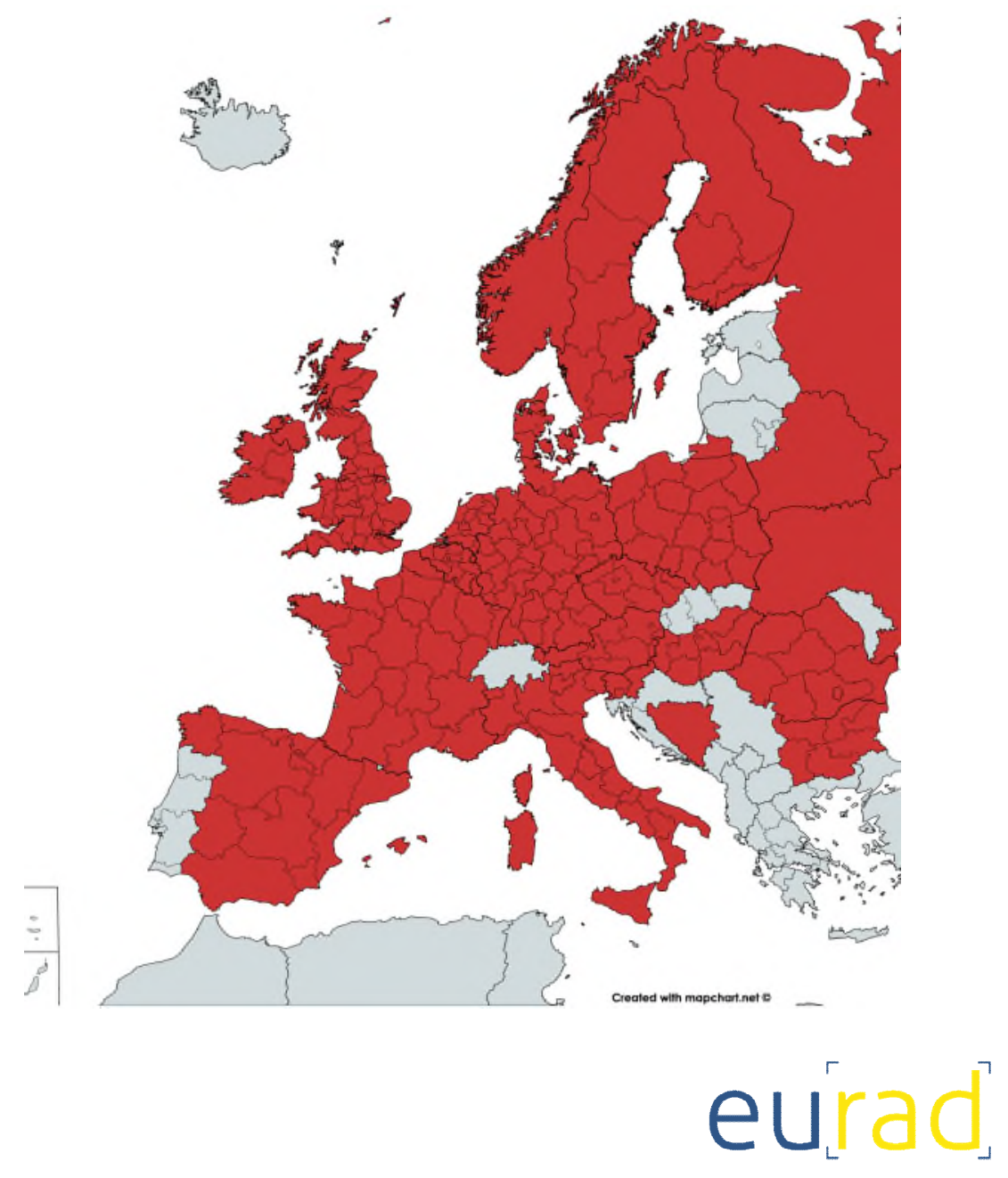




\section{CS LARGER GROUP - REPRESENTATIVENESS}

\section{- A well-balanced group:}

- Equilibrium between Western and Eastern countries

- Quite well-balanced gender representativity (9 Women and 13 Men)

- Good repartition between the categories of involved stakeholders (12 individual or/and local stakeholders and 10 national or/and European associations)

- 15 countries are represented in the CS larger group: Belgium, France, Germany, Italy, Norway, Sweden, United Kingdom, Bosnia and Herzegovina, Bulgaria, Czech Republic, Hungary, Poland, Slovakia, Slovenia, Ukraine

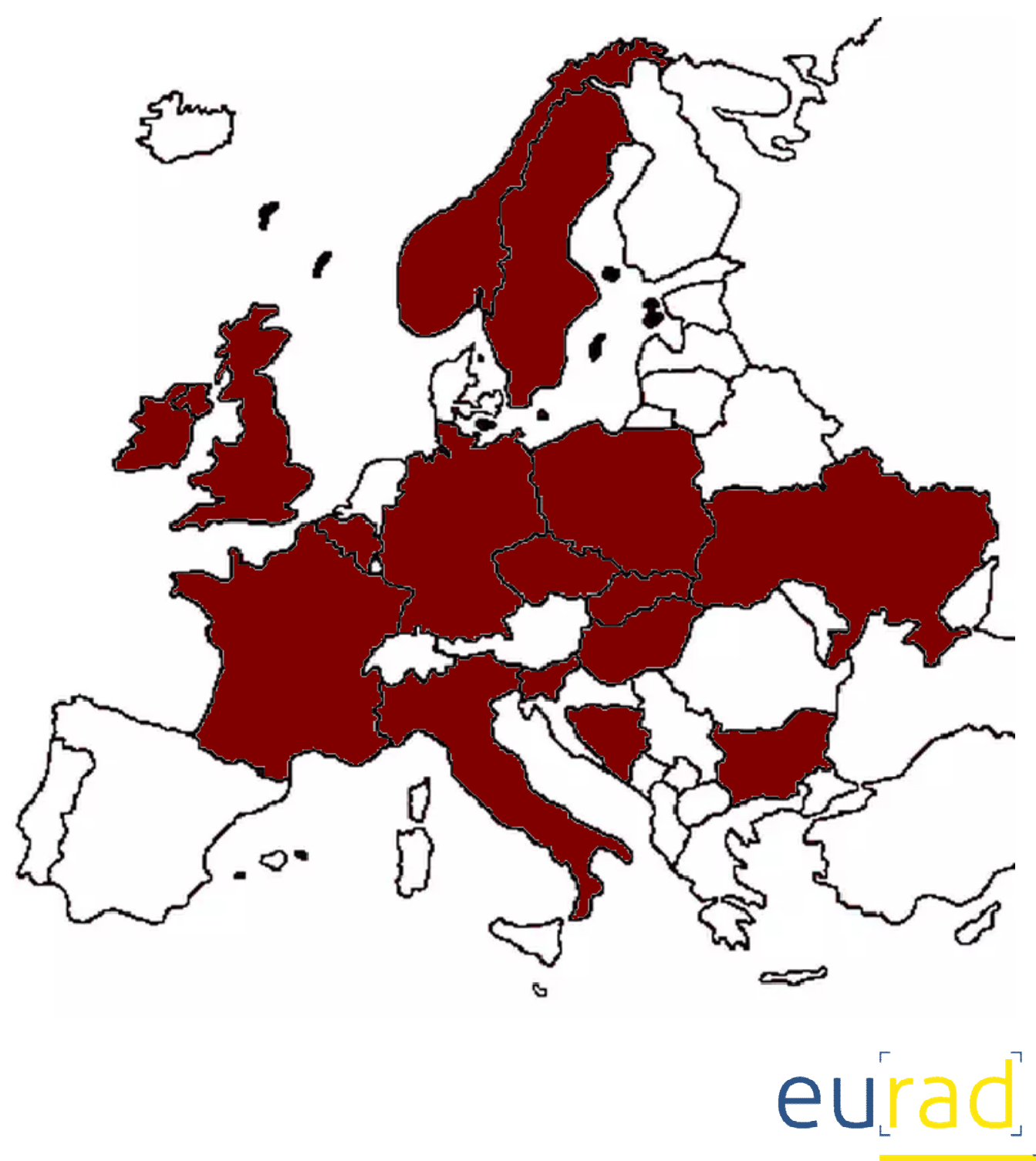




\section{STRUCTURE OF ICS ACTIVITIES IN EURAD}

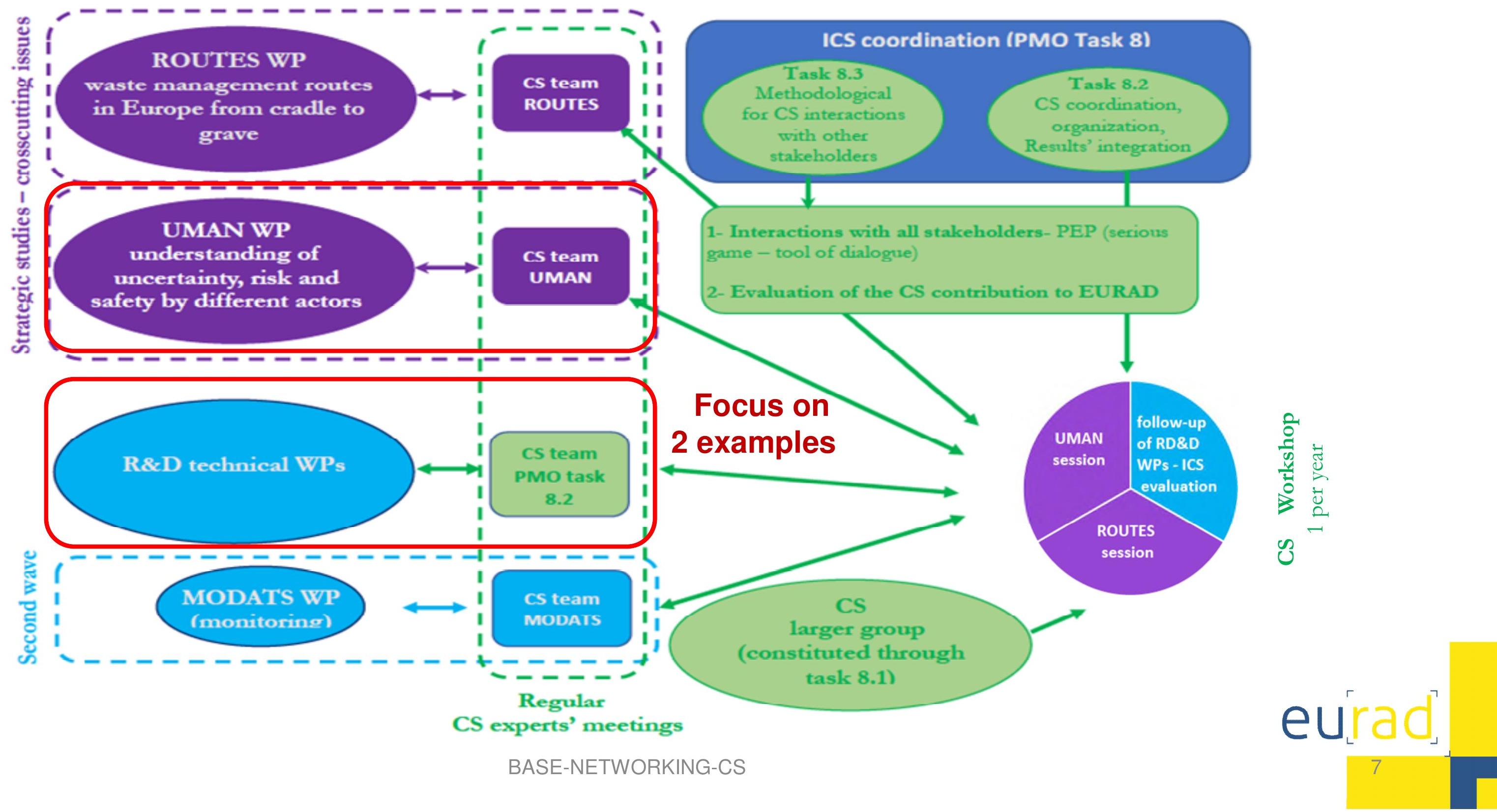




\section{UMAN PROJECT OBJECTIVES}

1- Develop a mutual understanding or at least to share different viewpoints among the different categories of actors on:

- uncertainty management and how it relates to risk \& safety

- whether and why a safety case is robust vis-à-vis uncertainties

2- Identify methods for organising a regular (intergenerational) and pluralistic dialogue on uncertainties during the development and review of the safety case 


\section{ICS ACTIVITIES IN UMAN}

- During yearly seminars, discussion of UMAN results with a pluralistic stakeholder group including EURAD researchers, Civil Society actors, regulators and international organisations (FSC of NEA)

- Integrative process - each seminar constitutes one step of a process of integration of UMAN results:

- Seminar 1: What uncertainty management involves for each type of actors?

- Seminar 2: Focus on Site and Geosphere related uncertainties

- Seminar 3: Focus on Human Aspects related uncertainties

- Seminar 4: Methods that can be used for discussing and organising pluralistic assessments of uncertainties throughout a disposal programme 


\section{METHODOLOGY FOR ELABORATING THE UMAN SEMINARS}

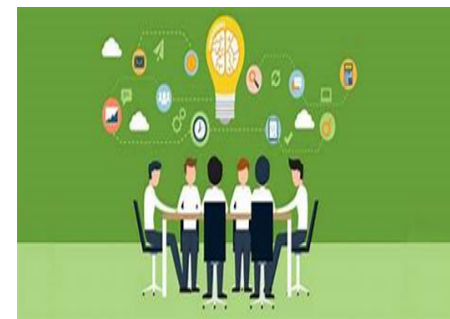

- Pluralistic teams for organising the seminars- inclusion of different views in the elaboration of seminars' frame

- Material for discussions is based on results achieved by UMAN in other tasks (on uncertainties characterisation, management options, etc)

- Elaboration of Keynotes presenting views of different types of actors (seminar 1)

- Selection of three topics of interest for pluralistic discussion related to Site of Geosphere (seminar 2)

- CS experts involved in UMAN work:

- review of the work performed by UMAN partners

- elaboration and administration of a questionnaire to CS larger group on uncertainties

- Identification of key CS priorities regarding the contribution to UMAN

- Discussion with CS larger group during UMAN session of the ICS workshops

- «Scenarios » \& « Key questions » are used as starting points to initiate exchanges \& views based on concrete cases 
- Seminar 1 (October 2020):

- "Unknown unknowns" : how to address them? How to live with them? How to be prepared to the unexpected?

- Independence of expertise : what does-it mean ? How it can be done in practice?

- Importance to consider uncertainty related to the process (governance issue), lot of ignored knowns factors to explore

- At the general level, agreement on the importance of uncertainty management in Safety Case, differences will appear in concrete implementation (according to cultural contexts, role of the actors in the process, risk appetite) 


\section{ICS ACTIVITIES IN UMAN - PRELIMINARY RESULTS}

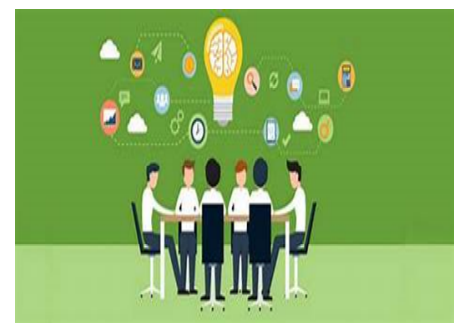

- Seminar 2 (October 2021):

- A stepwise, transparent \& flexible decision-making " process » is needed to manage Site and Geosphere uncertainties. It involves decisions regarding the selection and use of complementary measures at different programme phases:

- to avoid/reduce safety-significant uncertainties

- to mitigate residual uncertainties and manage «surprises » that could occur e.g. during construction \& through monitoring (even if very unlikely)

- CS should have the possibility and the means (i.e. access to independent expertise, legal provisions,...) to be involved early in this process and monitor the situation now \& in the future (several generations involved)

- Can it be addressed by the « Rolling stewardship » concept? 


\section{INTERACTIONS BETWEEN UMAN, CORI AND CS - CONTEXT}

- EURAD aims at enabling exchanges of results between actors and between projects

- CORI project (R\&D) objective is to improve the knowledge on the organic release issues which can influence the radionuclide behaviour in geological repositories for nuclear waste

- Interactions between UMAN \& CORI are foreseen in EURAD activities

- In this context, there is an on-going process to associate civil society in CORI-UMAN exchanges 


\section{INTERACTIONS BETWEEN UMAN, CORI AND CS - OBJECTIVES AND METHODOLOGY}

- What is the objective of fruitful interactions with civil society in Eurad?

- not a "technical cathedral"

- not reviewing every scientific report

- but having discussions with WMOs, TSOs and REs (3+1 dialogue)

- and giving some meanings to the results, by establishing links to the stakes of CS (safety of GD)

- towards "safety culture" (INSAG-4 \& SITEX-II) : intergenerational links

- Therefore, another way of working : focusing on uncertainties, and the linkage of it in technical WP as CORI.

- Idea- organisation of a workshop with crosscutting questions

- For example: how CORI results could change/challenge the uncertainties treatment developed in UMAN ? 


\section{eurad \\ European Joint Programme}

on Radioactive Waste Management

\section{QUESTIONS?}

\section{Julien Dewoghelaere (julien.dewo@mutadis.fr)}

The project leading to this application has received funding from the European Union's Horizon 2020 research and innovation programme under grant agreement $n^{\circ} 847593$.

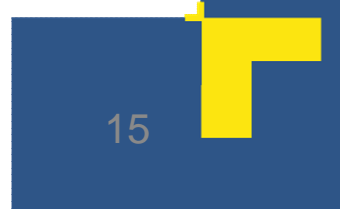

